\title{
nature
}

21 March 2002 Volume 416 Issue no 6878

\section{Pursuing arrogant simplicities}

Multidisciplinary research in biology requires the patience to distinguish untutored crassness from deceptively simple insights, and awareness from all participants of just how complex is even the simplest life-form.

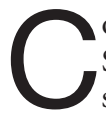
ommenting on the impact of physicists on biology after the Second World War, the physicist-turned-biologist Leo Szilard said: "What physicists brought to biology is not any skills acquired in physics, but rather an attitude: the conviction that few biologists had at that time, that mysteries can be solved." Physicists always tend to start simple. Is that wise, when confronting life?

Let no one underestimate the irritation that hypothetical simplicity can engender. Just consider the reactions to 'Daisyworld' (A. J. Watson \& J. E. Lovelock, Tellus 35B, 284-289; 1983). Jim Lovelock, the father of Gaia theory, described this model as "my proudest invention", but it continues to annoy biologists and Earth scientists to this day.

Lovelock's fictional planet covered with black and white daisies, adjusting its reflectivity and thus its temperature under a changing sun, was his answer to critics of his proposal that the combination of a planet and its life-forms could be self-regulating. The irritation that the model has engendered stems from both a proper scientific scepticism about its relevance to Earth, but also, at times, an improper defensiveness of traditional disciplinary boundaries.

In its own complex way, post-genomic biology maybe misleadingly simplistic about regulation. Generating vast sets of data from stressed cells in order to determine patterns of gene expression is an immense step forward. But beware the false impression that we are close to understanding how networks of genes regulate one another's expression, and generate phenotypes such as cellular development and behaviour.

Even the true scale of most genetic networks is unknown. And biologists know that genes are just one aspect of control: protein switches and molecular signalling networks are still a largely uncatalogued universe. It could be well over a decade before we might start to predict how self-contained subsets of networks — 'modules' — within a cell will behave under a specified perturbation, although qualities such as the modules' robustness are beginning to yield to network analysis.

How can the skills of physicists, chemists and engineers be brought to bear on these problems? Telling them to 'get real' by reading a biology textbook is fair advice, but not adequate. Even after one absorbs a thousand or more pages of text, one would still be unlikely to have a feel for the variability and complexity of even the simplest microbe. (Whether many biologists have a genuine feel for the organisms they study is a pertinent question, come to that.)

Seemingly every top-notch university in the United States has somewhere on its campus a building, newly completed or under construction, that is to bring together scientists from many disciplines to address some aspect of biology (see page 256 for a profile of Harvard's contribution to the genre). To their credit, some, like Stanford's Bio-X, are placing a high priority on multidisciplinary education for undergraduate and graduate students, rather than simply pulling researchers together and hoping that sparks will fly.

But while non-biologists need to be appropriately humble in the face of life's realities, they also need the confident faith arrogance, if you will - that such systems can be modelled and made predictable. But what if, as some biologists suggest, there may be no possible model simpler than life itself? Such are the defeatist speculations that physicists at least (as Szilard suggested) are schooled to ignore.

Especially in a multidisciplinary project, it's important to be able to distinguish between ignorant simple-mindedness and the simplicity of true insight. This is easily said but less easily done, as researchers, journal editors and funding agencies repeatedly discover. But those scientists of any discipline who immerse themselves in life's innards could yet find that deceptively simple hypotheses earn them respect from biologists who are drowning in data - even if that respect takes years of stubborn persistence to be earned.

\section{In search of sound science}

\section{Quality standards for US federal research could be useful - but only if industry acts in good faith.}

'S ound science' is one of those phrases repeated so often by politicians in recent years that it has come close to losing all meaning. In endless debates over this or that piece of environmental or health regulation, each side invokes 'sound science' to mean anything that supports its end of the argument.

Now US government agencies are being asked to bring more precision to the term. They will soon be required by law to ensure that the scientific information they disseminate meets standards for "quality, objectivity, utility, and integrity" (see page 249).

The move seems to have started as a manoeuvre by industrybacked groups - which helped to draft the law — to make it harder to enact federal regulations. But it could nevertheless prompt a useful discussion of what constitutes 'quality' research, and what the role of science should be in shaping policy.

In public discussion of guidelines for implementing the new law, scientists have argued, perhaps defensively, that the current system of peer review assures quality control. But peer review isn't infallible (see page 258), and President George W. Bush's White House, which casts a wary eye on federal regulation, calls for an additional standard of 'reproducibility'. By this it means that data and research methods supporting 'influential' government actions should be transparent enough for others to achieve the same result using the same tools.

In a world where everyone acts in good faith to practice 'sound science', that standard might be reasonable. But if industry uses the new law simply to gum up the regulatory process with legal challenges, or keeps sending scientists running back to the lab for one more test before accepting their results, this would be far from reasonable. If that happens, scientists and the wider public should rightly demand another kind of transparency - one in which industry lobbyists are required to come clean about their motives. 